\title{
Grafting of Multiwalled Carbon Nanotubes with Chicken Feather Keratin
}

\author{
Yoxkin Estévez-Martínez, ${ }^{1,2,3}$ Carlos Velasco-Santos, ${ }^{2,4}$ \\ Ana-Laura Martínez-Hernández, ${ }^{2,4}$ Guadalupe Delgado, ${ }^{5}$ Erick Cuevas-Yáñez, ${ }^{3}$ \\ Daniel Alaníz-Lumbreras, ${ }^{1}$ Sergio Duron-Torres, ${ }^{1}$ and Víctor M. Castaño ${ }^{2}$ \\ ${ }^{1}$ Facultad de Ingeniería Eléctrica, Universidad Autónoma de Zacatecas, Avenida Ramón López Velarde No. 801, \\ 98000 Zacatecas, ZAC, Mexico \\ ${ }^{2}$ Departamento de Ingenieria Molecular de Materiales, Centro de Fisica Aplicada y Tecnologia Avanzada, \\ Universidad Nacional Autónoma de México, Boulevard Juriquilla 3001, 76230, QRO, Mexico \\ ${ }^{3}$ Centro Conjunto de Investigación en Química Sustentable, UAEM-UNAM, Carretera Toluca-Atlacomulco Km.14.5, \\ 52000 Toluca, MEX, Mexico \\ ${ }^{4}$ División de Estudios de Posgrado e Investigación, Instituto Tecnológico de Querétaro, Avenida Tecnológico Esquina Mariano Escobedo, \\ Centro Histórico, 76000, QRO, Mexico \\ ${ }^{5}$ Instituto de Neurobiología, Universidad Nacional Autónoma de México, Campus UNAM-Juriquilla, 76230, QRO, Mexico \\ Correspondence should be addressed to Víctor M. Castaño; castano@fata.unam.mx
}

Received 10 January 2013; Revised 4 March 2013; Accepted 31 March 2013

Academic Editor: Tianxi Liu

Copyright (C) 2013 Yoxkin Estévez-Martínez et al. This is an open access article distributed under the Creative Commons Attribution License, which permits unrestricted use, distribution, and reproduction in any medium, provided the original work is properly cited.

\begin{abstract}
Keratin, obtained from chicken feathers, was grafted on the surface of commercially available carbon nanotubes. The original procedure developed allows a covalent interaction between some specific chemical groups characteristic of the keratin, with some functional groups introduced on purpose on the surface of the nanotubes, as revealed by infrared and Raman spectroscopies, which also allowed to determine structural changes introduced during the process, such as crystallinity, which lead to changes in other properties, as well.
\end{abstract}

\section{Introduction}

Carbon nanotubes (CNTs) have become one of the main focuses of contemporary materials science and engineering thanks to their extraordinary electrical, thermal, and mechanical properties [1] and the rolling up of the graphene sheet at a nanometer scale [2], high stiffness, and axial strength, as a result of the carbon-carbon $\mathrm{sp}^{2}$ bonding [3]. Also, thanks to the inherent graphene structure of the nanotube shell walls, the thermal conductivity of these materials approaches that of on-axis graphite [4]. The precise magnitude of these properties depends on the diameter and chirality of the nanotubes and whether they are single-walled (SWNTs), double-walled (DWNTs), or multiwalled nanotubes (MWNTs) in form [5].
Despite their low degree of crystallinity, CNTs still maintain high mechanical properties. This characteristic makes them ideal as reinforcing agents for high performance polymer nanocomposites. However, the high specific surface area (200 and $400 \mathrm{~m}^{2} / \mathrm{g}$ ) [6] results in a strong tendency to agglomeration. Nanoropes (agglomerates) due to Van der Waals forces are extremely difficult to disperse and align in a polymer matrix $[5,7]$. Thus, the way to improve the dispersion of the carbon nanotubes in a polymer matrix is the functionalization of CNTs $[5,8-10]$, in particular, covalent functionalization, for which one has first to generate defects on the surface of the carbon nanotubes by hydrolysis, thus forming the covalent bond.

On the other hand, keratin is a protein complex (biopolymer) formed by long chains with a molecular mass of 
approximately $10 \mathrm{kDa}$ [11]. Relevant to our purposes is to mention the numerous reactive side chains, which can form a variety of surface patterns as result of bending of the backbone, feature that makes it ideal to functionalize, in situ, the surface of carbon nanotubes. Keratin is a useful subject for the study of orientation because it occurs naturally in a $\alpha$-helix configuration in mammalian fibers such as hair and wool but predominantly adopts a $\beta$-sheet configuration in avian fibers such as feathers. These fibers, as well as keratin in skin, have been the target of a number of recent studies according to Rintoul et al. [12].

In this present work, multiwalled carbon nanotubes (MWNTs) were oxidized by hydrolysis to generate defects and different functional groups such as $-\mathrm{OH}$ and $-\mathrm{COOH}$ in its walls (MWOH's) $[13,14]$ aiming to be able to produce a novel hybrid organic-inorganic nanocomposite, through the grafting of keratin onto the carbon nanotubes.

\section{Experimental}

Multiwalled carbon nanotubes (MWNTs) were obtained from a commercial source, which produced them by chemical vapor deposition, with a diameter from 10 to $30 \mathrm{~nm}$ and 1 to $10 \mu \mathrm{m}$ long, with a purity $>90 \%$ and surface area of 90 to $350 \mathrm{~m}^{2} / \mathrm{g}$. $\mathrm{KMnO}_{4}$, urea 98\%, EDTA 90\%, 2-mercaptoethanol $98 \%$, tris-hydroxymethylamine $97 \%$ at a $\mathrm{pH}$ of $9.0, \mathrm{NHO}_{3}$ (95\%), and $\mathrm{H}_{2} \mathrm{SO}_{4}(98 \%)$ were purchased from a commercial supplier. The Bradford reactive was purchased also from a commercial supplier.

Based on previous reports $[9,13,15-18]$, the purification/oxidation of the MWNTs was achieved in liquid phase with a $3: 1$ mix of $\mathrm{NHO}_{3}(95 \%)$ and $\mathrm{H}_{2} \mathrm{SO}_{4}(98 \%)$ at $85^{\circ} \mathrm{C}$ for $3 \mathrm{~h}$ in a reflow process. The resulting material was vacuum washed to a neutral $\mathrm{pH}$ with deionized water.

Keratin was extracted from chicken feathers, as previously described $[11,19,20]$ as follows: $3 \mathrm{~g}$ of biofibre were solubilized using $75 \mathrm{~mL}$ of distilled water to form $8 \mathrm{M}$ urea 98\%, 3 mM EDTA 90\%, 2-mercaptoethanol 98\%, and $200 \mathrm{mM}$ tris-hydroxymethylamine $97 \%$ at a $\mathrm{pH}$ of 9.0 . The mixture was left at room temperature under stirring for $24 \mathrm{~h}$. The keratin extracted in saline solution passes through a process of dialysis, due to the presence of salts such as urea. Dialyzed solution was preserved at $4^{\circ} \mathrm{C}$.

Infrared (FTIR) spectra were recorded in a Vector 33 Bruker spectrophotometer at 32 scans, with a resolution of $4 \mathrm{~cm}^{-1}$. Solid samples were imbedded in $\mathrm{KBr}$ disks. Raman spectra were recorded in a Micro-Raman Dilor with a resolution of $515 \mathrm{~cm}^{-1}$, with a $514.5 \mathrm{~nm}$ laser with $15 \mathrm{~s}$ of integration time. The microplate reader was a Bio-Rad Model $680 \mathrm{XR}$ to $100 \mathrm{~V}, 50 \mathrm{~Hz}$, and $550 \mathrm{~nm}$. Elemental analysis by combustion has been performed under the following experimental conditions: the sample was weighed on a microbalance Mettler Toledo model XP6 and analyzed at a combustion temperature of $1150^{\circ} \mathrm{C}$ and a reduction temperature of $850^{\circ} \mathrm{C}$ in an elemental analyzer from elemental model vario-MICRO-cube. Oxygen 99.996\% was the combustion gas, and helium 99.997\% was gas carrier. Each sample was analyzed by duplicate. The analyses X-ray Photoelectron Spectrometer (XPS) were performed with a JPS-9200 Photoelectron Spectrometer (ESCA).

Covalent functionalization of the previously oxidized multiwalled carbon nanotubes (MWOHs) with keratin was done $[19,20]$ by using $0.25 \%$ (wt/v) $\mathrm{KMnO}_{4}, 0.33 \%(w t / v)$ malic acid, and 5\% (v/v) $\mathrm{H}_{2} \mathrm{SO}_{4}(98 \mathrm{wt} \%)$. These concentrations are constant at $55^{\circ}, 65^{\circ}$, and $75^{\circ} \mathrm{C}$ for $2 \mathrm{~h}$ with MWOHs/ keratin $1: 1,1: 2$, and $1: 3$ (wt/wt). In the REDOX reaction, the malic acid/ $\mathrm{KMnO}_{4}$ implicates the generation of macroradicals formed by the attack of the species to primary radicals of the peptide bonds. The keratin has hanging functional groups as $-\mathrm{NH}_{2},-\mathrm{COOH},-\mathrm{SH}$, and $-\mathrm{OH}$, which can form covalent bonds with functional groups $\mathrm{COOH}$ and $\mathrm{COO}-$ present in the walls of the MWOHs. Samples prepared are described in Table 1.

Bradford analysis [21] was employed to quantify the degree of keratin grafting onto the oxidized multiwalled carbon nanotubes, thanks to the color changes, from red to blue, due to the union of the coloring agent to the protein. From an aliquot $(60 \mu \mathrm{L})$ of keratin-g-MWOHs solution $(80 \mu \mathrm{g} / \mathrm{mL})$ $4.8 \mathrm{~g}$ of solid sample is obtained. A calibration curve, by using known solutions of bovine serum albumin protein (BSA $50 \mu \mathrm{g} / \mathrm{mL}$ ) in a range of 0 to $4 \mu \mathrm{g}$ of protein by final volume, was produced. With the linear fit of the resulting curves, the $R$-Square $\left(R^{2}\right)$ is obtained [22].

\section{Results and Discussion}

The purification procedure developed here removed most of the amorphous carbon and catalyst residues on the MWNTs, as was confirmed by spectroscopy, thus obtaining oxidized multiwalled carbon nanotubes, key for the covalent interaction (grafting) with the keratin. Figure 1 shows the calibrated absorbance curve, prepared using bovine serum albumin, which allowed quantify the keratin on the surface of the MWOHs.

Table 2 summarizes the quantification of keratin grafted in the carbon nanotubes according to absorbance experiments with Bradford assay, where the sample CK7511 (1:1 wt/wt MWOHs/Keratin ratio to $75^{\circ} \mathrm{C}$ conditions) contain the highest percentage of keratin grafted in contrast to the $65^{\circ} \mathrm{C}$ case, with 1:1 wt/wt MWOHs/Keratin ratio (CK6511) which contains the least quantity. On average, the reaction condition at $55^{\circ} \mathrm{C}$ with $1: 3 \mathrm{wt} / \mathrm{wt} \mathrm{MWOHs} /$ keratin ratio (CK5513) is the most representative.

Raman spectra can be regarded as a sort of fingerprint of nanostructured carbon $[23,24]$. The Raman spectra of the MWNTs pristine, oxidized and all grafted samples with keratin show three important bands at $\sim 1570 \mathrm{~cm}^{-1}$ (G band), $\sim 1340 \mathrm{~cm}^{-1}$ (D band), and $\sim 2684 \mathrm{~cm}^{-1}$ ( $\mathrm{D}^{\prime}$ band) which have been reported by several groups [23, 25-33], as can be observed in Figure 2.

The $G$ band in carbon nanotubes involves an optical phonon mode between the two dissimilar carbon atoms in the unit cell. It is known to originate from $\mathrm{sp}^{2}$ carbon sites present in the sample [31]. This band essentially represents the $v(\mathrm{C}=\mathrm{C})$ stretching vibration of all pairs of $\mathrm{sp}^{2}$ atoms in the ring. According to group theoretical analysis, the $G$ band 


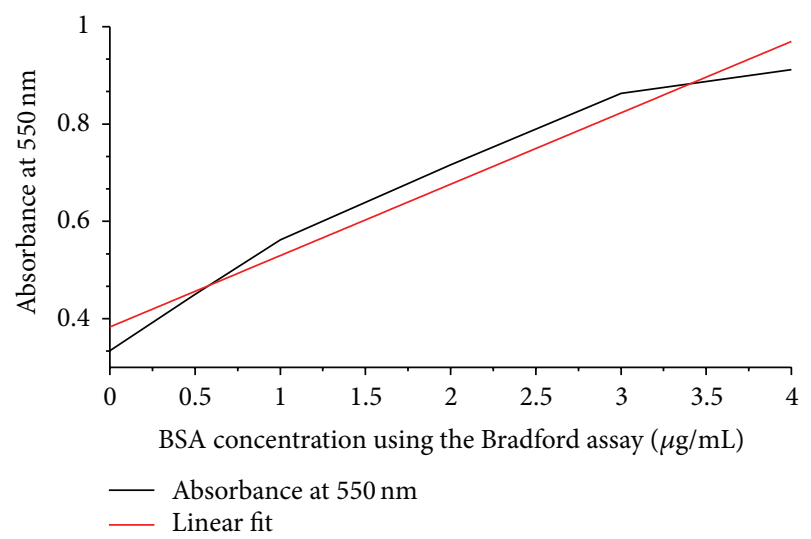

\begin{tabular}{|l|c|c|c|}
\hline Equation & $y=a+b * x$ & & \\
\hline $\begin{array}{l}\text { Residual sum of } \\
\text { squares }\end{array}$ & 0.01065 & & \\
\hline Pearson's $r$ & 0.97907 & & \\
\hline Adj. $R^{2}$ & 0.94821 & & \\
\hline & & Value & Standard error \\
\hline $\begin{array}{l}\text { Absorbance at } \\
550 \mathrm{~nm}\end{array}$ & Intercept & 0.39762 & 0.03363 \\
\cline { 2 - 4 } & Slope & 0.14407 & 0.01498 \\
\hline
\end{tabular}

FIGURE 1: Absorbance $(550 \mathrm{~nm})$ versus BSA concentration $(\mu \mathrm{g} / \mathrm{mL})$ in a range of 0 to $4 \mu \mathrm{g} / \mathrm{mL}$. The Bradford assay demonstrates a linear regression with increasing BSA concentrations, $y=0.1441 x+$ $0.3976, R^{2}=0.9586$.

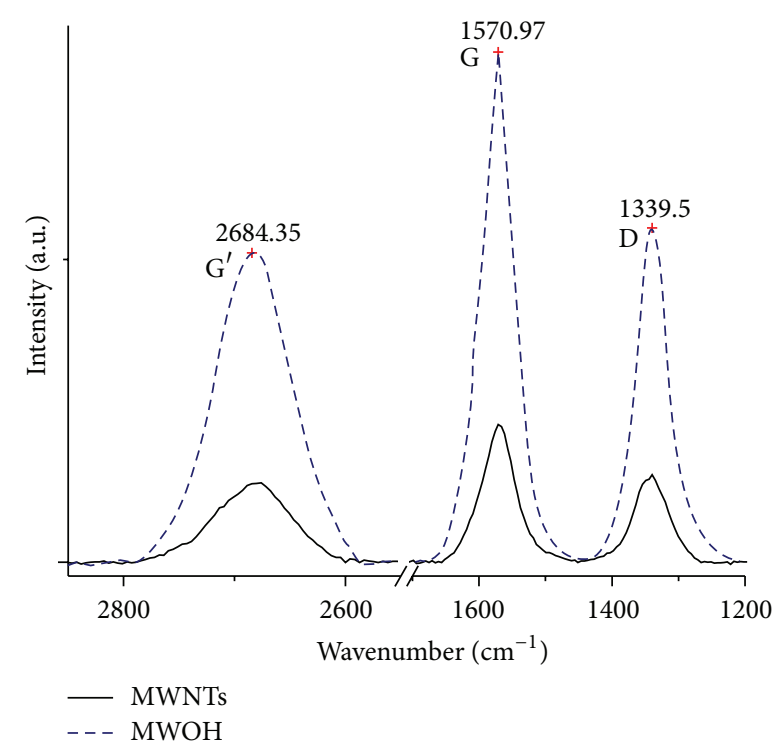

FIGURE 2: Characteristics peak bands Raman of multiwalled carbon nanotubes. Here MWNTs and MWOHs.

corresponds to the $\mathrm{E}_{2 \mathrm{~g}}$ modes and has been assigned to the movement in opposite directions of two neighboring carbon atoms in a graphite sheet [23]. The second signal (D band) is due to the disorder present in the MWNTs [23]. D band had been assumed to be associated with both the presence of disorder and finite size effect of carbons; this did not always mean that it could originate only because of the disorder present in the material [31]. The D band as characteristic for
TABLE 1: Concentrations (wt/wt) and temperatures $\left({ }^{\circ} \mathrm{C}\right)$ used for MWOH's-g-Keratin grafting.

\begin{tabular}{lccc}
\hline Concentration & \multicolumn{3}{c}{ Temperature } \\
& $55^{\circ}$ & $65^{\circ}$ & $75^{\circ}$ \\
\hline $1: 1$ & CK5511 & CK6511 & CK7511 \\
$1: 2$ & CK5512 & CK6512 & CK7512 \\
$1: 3$ & CK5513 & CK6513 & CK7513 \\
\hline
\end{tabular}

disordered graphite shows quite significant dependency of its intensity on the excitation wavelength. It is to be noted that this graphitic lattice vibration mode has been assigned to $A_{1 g}$ symmetry [31]. Also, in a review recently [33], the $\mathrm{D}$ band is attributable to the presence of disordered amorphous carbon, double resonance effects in $\mathrm{sp}^{2}$ carbon. The frequency of the $\mathrm{D}$ band peak increases with increasing laser energy [33]. Note that this peak results from amorphous carbon, not defects, in the tube walls [33]. Finally show one broadband assigned to the $\mathrm{G}^{\prime}$ band to $\sim 2684 \mathrm{~cm}^{-1}$. The $\mathrm{G}^{\prime}$ band observed in the Raman spectra of all the carbonaceous materials, which is basically the second harmonic of the D band [31,34], appears at $\sim 2 \omega \mathrm{D}$ wavenumber position, when $\mathrm{sp}^{2}$ bonded carbon atoms are present [31]. This peak exhibits a strong dispersive behavior as a function of excitation energy [31]. DiLeo et al. show decreasing the intensity of $\mathrm{G}^{\prime}$ band directly with mass fraction decreases of the MWNTs is also evident [35].

Since the $\mathrm{G}^{\prime}$ band results from a two-phonon process, it is plausible that its intensity should decrease as the sample becomes less ordered (i.e., more impurities present) not allowing for the coupling effect which is necessary for the two-phonon process [35]. The relative changes in the various peak intensities clearly correlate with the amount of carbonaceous impurities [35]. In our samples, the Raman intensities are summarized in Table 3 . A change in the $D / G$ area ratio of MWNTs in a covalent functionalization is possible by modifying the external walls of carbon nanotubes [23] and, as a function of MWNts purity, there are changes in the Raman peak ratios (i.e., $D / G, G^{\prime} / G$, and $G^{\prime} / D$ ). Further evidence of this is the $G^{\prime} / D$ ratio, since the $G^{\prime}$ band is a specific indicator of MWNTs purity and the D band is due to nano-carbons (presence of disordered carbons phases), therefore, the higher the value, the purer.

The oxidation of multiwalled carbon nanotubes (MWOHs) was also confirmed by FTIR. The vibrational normal modes of MWNTs in infrared spectroscopy are $A_{2 u}$ and $\mathrm{E}_{1 \mathrm{u}}$, near to 868 and $1575 \mathrm{~cm}^{-1}$ [36]; however, Kuhlmann et al. [37] refer to 850 and $1590 \mathrm{~cm}^{-1}$. In our samples, these modes are present, with a slight shoulder at $\sim 1580 \mathrm{~cm}^{-1}$ for $\mathrm{E}_{1 \mathrm{u}}$ and $\sim 800 \mathrm{~cm}^{-1}$ for $\mathrm{A}_{2 \mathrm{u}}$. In Figure 3 the spectra confirmed the oxidation of multiwalled carbon nanotubes [38]. The $1726 \mathrm{~cm}^{-1}$ band is due to $v(\mathrm{C}=\mathrm{O})$ present in the carboxylic groups $(\mathrm{COOH})$. At a wavenumber of $1466 \mathrm{~cm}^{-1}$ appears the vibration $\delta(\mathrm{O}-\mathrm{H})$ present in the carboxyl groups; however, in this zone the vibrations $v(\mathrm{C}-\mathrm{O})$ are present too. Also, according to Stobinski et al. [39], the spectra indicate intense bands at $3443 \mathrm{~cm}^{-1}$ (stretching vibrations of isolated surface $-\mathrm{OH}$ moieties and/or $-\mathrm{OH}$ in carboxyl groups and in sorbed 
TABLE 2: Quantification of keratin in carbon nanotubes, where the average concentration of protein in the samples refers to keratin/MWOH weight.

\begin{tabular}{lccccc}
\hline Sample & $\begin{array}{c}\text { Sample concentration } \\
(\mu \mathrm{g} / \mathrm{mL})\end{array}$ & $\begin{array}{c}\text { Sample amount in the } \\
\text { aliquot of the analysis }(\mu \mathrm{g})\end{array}$ & $\begin{array}{c}\text { Absorbance } \\
(\text { average })\end{array}$ & $\begin{array}{c}\text { Average amount of protein } \\
\text { found in the sample }(\mu \mathrm{g})\end{array}$ & $\begin{array}{c}\text { Average concentration of } \\
\text { protein in the sample }(\mu \mathrm{g} / \mu \mathrm{g})\end{array}$ \\
\hline CK7511 & $\mathbf{8 0}$ & $\mathbf{4 . 8}$ & $\mathbf{0 . 7 4 4}$ & $\mathbf{2 . 4 0 3 9}$ & $\mathbf{0 . 5 0 0 8}$ \\
CK7512 & 80 & 4.8 & 0.5245 & 0.8806 & 0.1835 \\
CK7513 & 80 & 4.8 & 0.5215 & 0.8598 & 0.1791 \\
CK6512 & 80 & 4.8 & 0.5175 & 0.8321 & 0.1733 \\
CK5513 & $\mathbf{8 0}$ & $\mathbf{4 . 2}$ & $\mathbf{0 . 4 9 1 5}$ & $\mathbf{0 . 6 5 1 6}$ & $\mathbf{0 . 1 5 5 2}$ \\
CK5512 & 80 & 4.8 & 0.4855 & 0.61 & 0.1271 \\
CK6513 & 80 & 4.8 & 0.4765 & 0.5475 & 0.1141 \\
CK5511 & 80 & 4.8 & 0.453 & 0.3845 & 0.0801 \\
CK6511 & $\mathbf{8 0}$ & $\mathbf{4 . 8}$ & $\mathbf{0 . 4 1 7}$ & $\mathbf{0 . 1 3 4 6}$ & $\mathbf{0 . 0 2 8}$ \\
\hline
\end{tabular}

TABLE 3: Value of area (Raman intensity) of peak bands $G^{\prime}, G$, and D, intensity ratio, and average purity of multiwalled carbon nanotubes pristine, oxidized, and grafts.

\begin{tabular}{|c|c|c|c|c|c|c|c|}
\hline Samples & $\mathrm{G}^{\prime}$ & G & $\mathrm{D}$ & $\mathrm{D} / \mathrm{G}$ & $\mathrm{G}^{\prime} / \mathrm{G}$ & $\mathrm{G}^{\prime} / \mathrm{D}$ & Average purity \\
\hline MWNTs & 52984.64 & 106422.15 & 96501.88 & 0.91 & 0.50 & 0.55 & 0.65 \\
\hline CK6512 & 184440.54 & 286488.59 & 211527.25 & 0.74 & 0.64 & 0.87 & 0.75 \\
\hline CK5512 & 489556.81 & 725777.39 & 493901.68 & 0.68 & 0.67 & 0.99 & 0.78 \\
\hline CK6511 & 385657.86 & 577481.65 & 339403.68 & 0.59 & 0.67 & 1.14 & 0.80 \\
\hline CK7511 & 96366.27 & 131668.86 & 81216.82 & 0.62 & 0.73 & 1.19 & 0.85 \\
\hline CK7512 & 38067.09 & 48136.99 & 29776.62 & 0.62 & 0.79 & 1.28 & 0.90 \\
\hline CK6513 & 238496.36 & 303557.99 & 181044.39 & 0.60 & 0.79 & 1.32 & 0.90 \\
\hline CK5513 & 240954.31 & 279484.06 & 193698.81 & 0.69 & 0.86 & 1.24 & 0.93 \\
\hline CK5511 & 275368.73 & 312627.18 & 232315.34 & 0.74 & 0.88 & 1.19 & 0.94 \\
\hline MWOHs & 373647.98 & 431840.08 & 284336.83 & 0.66 & 0.87 & 1.31 & 0.95 \\
\hline CK7513 & 236904.60 & 270755.23 & 169146.64 & 0.62 & 0.87 & 1.40 & 0.97 \\
\hline
\end{tabular}

TABle 4: Percentage of elemental analysis of $\mathrm{C}, \mathrm{H}, \mathrm{N}$, and $\mathrm{S}$ of MWNTs, MWOHs, CK7511, CK5513, and CK6511.

\begin{tabular}{lcccc}
\hline Sample & $\% \mathrm{C}$ & $\% \mathrm{H}$ & $\% \mathrm{~N}$ & $\% \mathrm{~S}$ \\
\hline MWNTs & 92.75 & 0.19 & 0.00 & 0.02 \\
MWOHs & 92.66 & 0.43 & 0.00 & 0.00 \\
CK7511 & 74.35 & 1.68 & 2.69 & 0.66 \\
CK5513 & 79.01 & 1.73 & 2.47 & 0.51 \\
CK6511 & 83.12 & 1.11 & 1.29 & 0.35 \\
\hline
\end{tabular}

water). The shifts in characteristic wavenumbers toward lower wavenumbers indicate the presence of strong hydrogen bonds between - $\mathrm{OH}$ groups. The bands in the 1750$1550 \mathrm{~cm}^{-1}$ range can be assigned to $\mathrm{C}=\mathrm{O}$ groups in different environments (carboxylic acid, ketone/quinone) and to $\mathrm{C}=\mathrm{C}$ in aromatic rings, whereas the bands in the range of $1300-950 \mathrm{~cm}^{-1}$ show the presence of $\mathrm{C}-\mathrm{O}$ bonds in various chemical surroundings [33]. A band near $1466 \mathrm{~cm}^{-1}$ is due to sorbed water ( $\mathrm{OH}$ in-plane deformation), and overlapping bands in region characteristic for $\mathrm{C}-\mathrm{O}$ moiety, for example, $\mathrm{C}-\mathrm{O}-\mathrm{C}$ (structure of oxides, oxygen bridges, etc.) are present in the FTIR transmission spectra of multiwalled carbon nanotubes pristine. The relative increase and partial separation of bands in the $1250-950 \mathrm{~cm}^{-1}$ wave region point to increase in the amounts of hydrated surface oxides $(\mathrm{O}-\mathrm{H}$ deformation and $\mathrm{C}-\mathrm{O}$ stretching combination in surface phenols, hydroquinones, and aromatic carboxylic acids).

Figure 4 shows the characteristic vibrations of dialyzed keratin according to the amino acids present in the structure of the keratin [40-43]. The protein IR absorption is visible as an amino acid side-chain absorption and normal modes of the amide group. Amino acid side-chain absorption provides valuable information when the mechanism of protein reactions is investigated. This is because side chains are often at the heart of the molecular reaction mechanism. The vibrational normal modes of the amide groups are due to the contribution of the internal coordinates, when the amide groups are incorporated into a polypeptide [41, 43]. In Figure 4 of the keratin dialyzed spectrum, there is no evidence of cysteine $v(\mathrm{SH})$ in the $2550-2600 \mathrm{~cm}^{-1}$ region of the infrared spectrum but there are carbonyl groups of protonated carboxyl groups $\left(1710-1790 \mathrm{~cm}^{-1}\right)$ because, in the dialyzed keratin, the cysteine is oxidized. Intensity values for the vibrations correspond to cysteic acid monoxide $\nu_{s}\left(1077 \mathrm{~cm}^{-1}\right)$, cysteic acid dioxide $\nu_{s}\left(1125 \mathrm{~cm}^{-1}\right)$ and $\nu_{a}(\mathrm{~S}-\mathrm{O})$ $\left(1170 \mathrm{~cm}^{-1}\right)$.

The aliphatic moieties of amino acid side chains give rise to several absorbance bands of medium to weak intensity. While the $\delta$ as $\left(\mathrm{CH}_{3}\right)$, the $\delta\left(\mathrm{CH}_{2}\right)$, and the $\delta \mathrm{s}\left(\mathrm{CH}_{3}\right)$ vibrations 


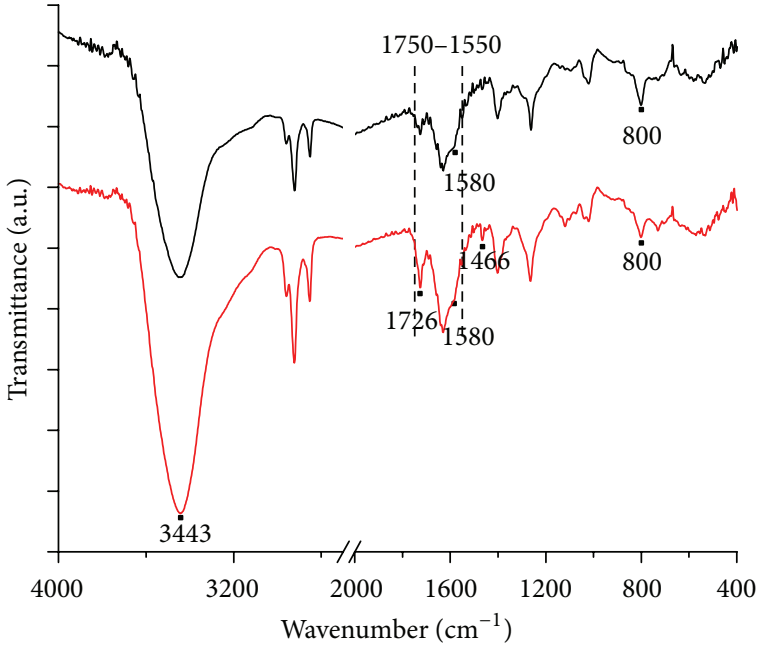

- MWNTs

- MWOHs

FIGURE 3: Infrared (FTIR) spectra of MWNTs and MWOHs.

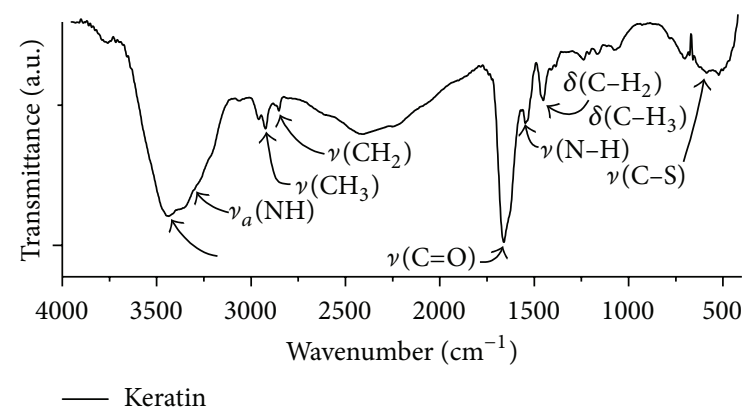

FIGURE 4: Infrared (FTIR) spectra of dialyzed keratin.

between 1445 and 1480,1425 and 1475 , and near to $1385 \mathrm{~cm}^{-1}$ are more intense when next to a C-O group [41], the $\delta(\mathrm{CH})$ is representative between 1315 and $1350 \mathrm{~cm}^{-1}$ [41]. The frequency of the $\delta\left(\mathrm{CH}_{2}\right)$ vibration of aspartic acid and glutamic acid residues is sensitive to the protonation state and the $\delta \mathrm{s}\left(\mathrm{CH}_{3}\right)$ vibration to the branching of the hydrocarbon chain [44]. Additionally, the characteristic infrared bands of these amino acid side chains are to 1720 of $\mathrm{C}=\mathrm{O}$ stretching and 1560 of $\mathrm{CO}_{2}-$ asymmetric stretching [45].

Of the different structures of aliphatic amino acids, the proline (Pro) is remarkable for not forming the usual amide group with the amino acid that precedes in the sequence, but rather an $\mathrm{N}, \mathrm{N}$-disubstituted amide group due to the additional linkage of the side chain to the amide $\mathrm{N}$-atom. The Pro amino acid is present with $\nu(\mathrm{CN})$ band near $1430 \mathrm{~cm}^{-1}$ [44].

Of the aromatic side chains, the tyrosine is a relatively strong infrared absorber due to its polar character, and its bands originated from the $v(\mathrm{CC})$, the $v(\mathrm{C}-\mathrm{O})$, and the $\delta(\mathrm{COH})$ mode near 1517,1238 , and $1209 \mathrm{~cm}^{-1}$. The phenylalanine band is covered by a peak of greater intensity, which is not observable at the intensity of $1498 \mathrm{~cm}^{-1}$; however, at 1334 and $1455 \mathrm{~cm}^{-1}$, the tryptophan is seen with a little intensity, due to the small amount in grams of this amino acid in keratin $[20,44]$.

The bond peptide of the protein is characteristic of the amide groups. The amide II stretching occurs by bending in the plane $\delta(\mathrm{NH})$ group and $\nu(\mathrm{CN})$, with contributions in the planes from $v(\mathrm{CC}), \delta(\mathrm{CO})$, and $\nu(\mathrm{NC})$. The amide III stretching depends on the chain structure with the combination of $\delta(\mathrm{NH})$ in the plane, $v(\mathrm{CN}), v(\mathrm{CC})$, and $\delta(\mathrm{CO})$. In the above, at $3293 \mathrm{~cm}^{-1}$ is clear the stretching $\nu(\mathrm{NH})$ of amide $\mathrm{A}$, and $3069 \mathrm{~cm}^{-1}$ belongs to $v_{a}(\mathrm{NH})$ of amide B [20]; therefore, this is related to the $\beta$ or extended polypeptide chain, class of fibrous proteins [46]. It is exclusively localized on the $\mathrm{NH}$ group and is therefore in proteins insensitive to the conformation of the polypeptide backbone [41].

Near to 2930 and $2850 \mathrm{~cm}^{-1}$ are present characteristic infrared bands of aliphatic hydrocarbons of methylene asymmetric $\mathrm{C}-\mathrm{H}$ stretching and symmetric $\mathrm{C}-\mathrm{H}$ stretching, respectively [45]. However, for keratin protein, the methyl $\left(\mathrm{CH}_{3}\right)$ asymmetric and symmetric modes are observed at 2955 and $2933 \mathrm{~cm}^{-1}$, respectively, and the methylene $\left(\mathrm{CH}_{2}\right)$ asymmetric and symmetric modes at 2875 and $2855 \mathrm{~cm}^{-1}$ [47]. Therefore, similar to the above, the band at $2929 \mathrm{~cm}^{-1}$ is assigned to $v\left(\mathrm{CH}_{3}\right)$, and the band at $2858 \mathrm{~cm}^{-1}$ corresponds to $\nu\left(\mathrm{CH}_{2}\right)$; both signals originated from keratin and can be assigned to the aliphatic chain, that is, increased with grafting in carbon nanotubes, similar to chemical modification of keratin biofibers by graft polymerization of methyl methacrylate using redox initiation [20]. The infrared spectrum has a slightly parallel amide I component at $1660 \mathrm{~cm}^{-1}$. This band has been reasonably assigned to polypeptide chains; in an unordered state corresponding slightly perpendicular amide II bands are found at $1544 \mathrm{~cm}^{-1}[42,48,49]$; these peaks were assigned to a $\alpha$-helical component $[41,42]$.

The $1800-1500 \mathrm{~cm}^{-1}$ region (Figure 5) contains the important amide I and II modes, $v(\mathrm{CONH})$ and $\delta\left(\mathrm{NH}_{2}\right)$, respectively, of the keratin. A strong band was reported in the $1652 \mathrm{~cm}^{-1}$ and was assigned to the $\nu(\mathrm{C}=\mathrm{O})$ stretching amide I vibration band, showing that the $\alpha$-helix exists predominantly conformation [50]. Conversely, a strong band at $1666 \mathrm{~cm}^{-1}$ corresponds to the $\nu(\mathrm{C}=\mathrm{O})$ stretching amide I vibration of a $\beta$-sheet conformation. Therefore, it is possible to observe a weaker shoulder on this strong band for the amide I $\beta$-sheet conformation, indicating that the keratin contained both $\alpha$-helix and $\beta$-sheet conformations [50]. In summary, amide $I$ is in the range of 3360-3340 for asymmetric $\mathrm{NH}_{2}$ stretching, 3190-3170 for symmetric $\mathrm{NH}_{2}$ stretching, $1680-1660$ for $\mathrm{C}=\mathrm{O}$ stretching, and $1650-1620$ for $\mathrm{NH}_{2}$ bending [45].

A strong amide II band is observed at $1546 \mathrm{~cm}^{-1}$ and a weaker shoulder at $1521 \mathrm{~cm}^{-1}$. Peptides and proteins with an antiparallel $\beta$-sheet structure have strong amide II bands at $1534 \mathrm{~cm}^{-1}$; a parallel $\beta$-sheet structure is found at $1646 \mathrm{~cm}^{-1}$. Inspection of both amide I and II generally provides little help in distinguishing between turn and sheet conformation. In favorable situations, however, the amide II band may assist in assigning random structure and allow a more accurate estimate of the helix and random components [51]. 


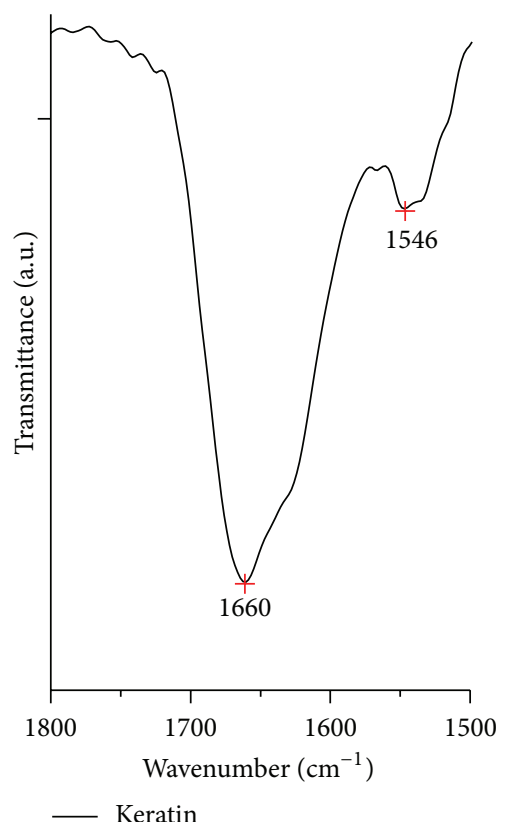

(a)

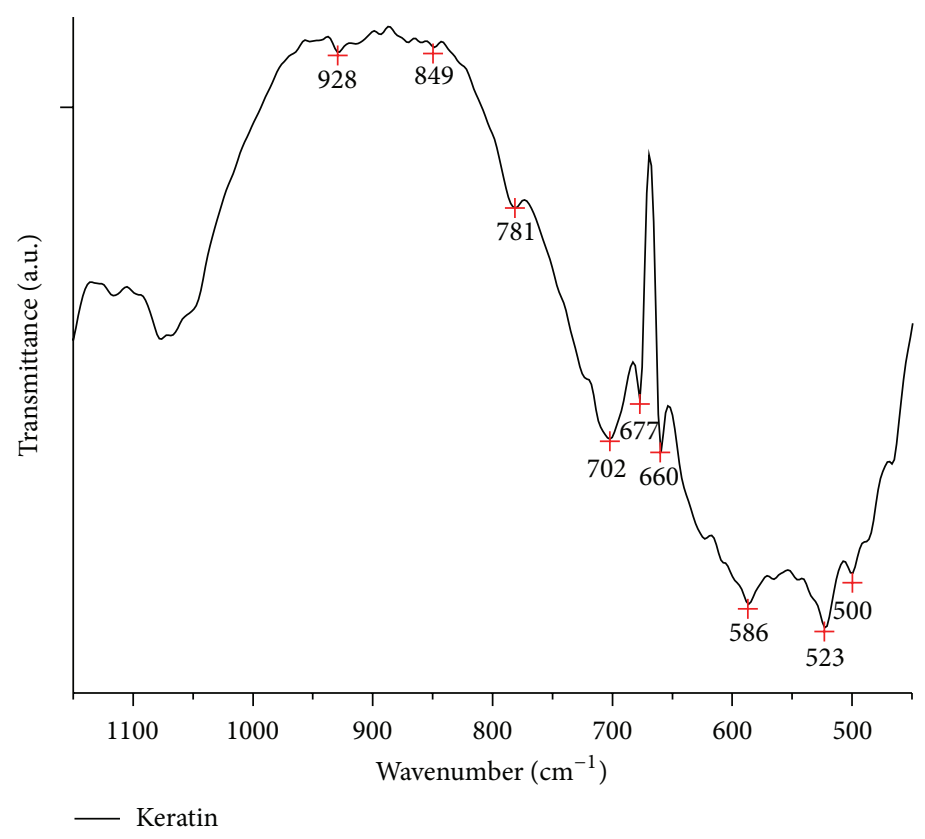

(b)

FIGURE 5: Detail of the keratin dialyzed IR spectrum in $1800-1500$ and $1100-450 \mathrm{~cm}^{-1}$ regions.

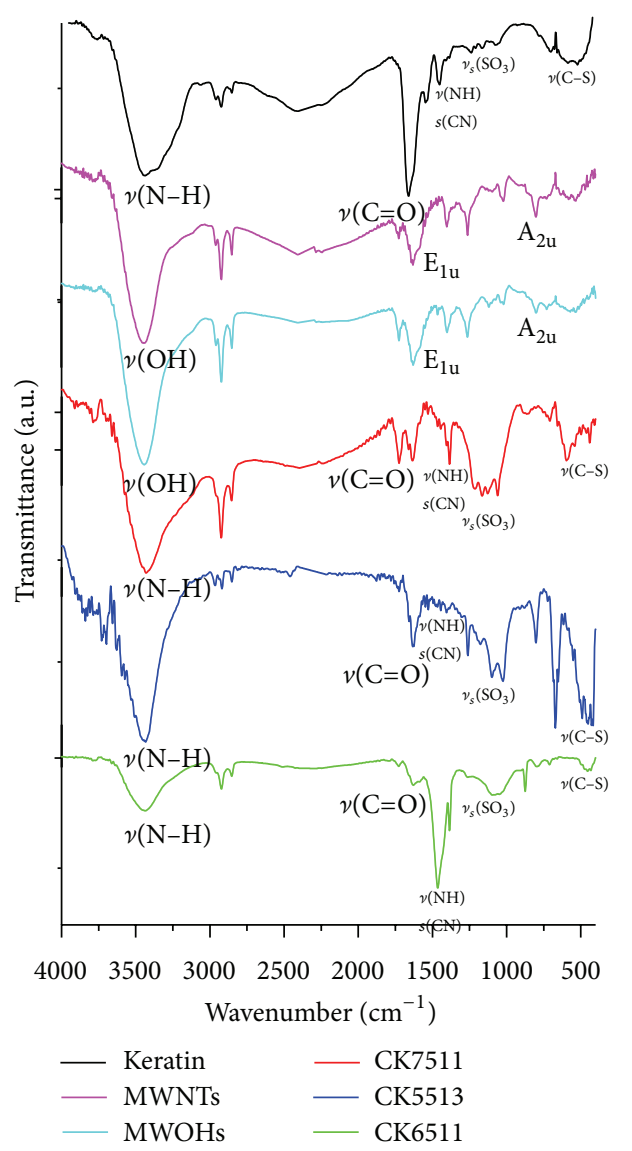

FIGURE 6: FTIR spectra of the nfr most representative samples of multiwalled carbon nanotubes pristine, oxidize, and grafted with keratin at different reaction temperatures (i.e., $75^{\circ}, 55^{\circ}$, and $65^{\circ} \mathrm{C}$ ) with various weight ratios MWOHs/keratin.
Spectral features in the $1000-450 \mathrm{~cm}^{-1}$ regions (Figure 5) are the $\mathrm{C}-\mathrm{S}$ stretching modes in the spectra of alkyl thiols appearing in the $730-620 \mathrm{~cm}^{-1}$ region. For methionine, there is a correlation between the frequency of the $\mathrm{C}-\mathrm{S}$ stretching vibration and the conformation of the $-\mathrm{S}-\mathrm{CH}_{3}$ group relative to the $\mathrm{CH}_{2}-\mathrm{CH}_{2}-$ groups. In addition to the bands of amide I and III, two bands at $960-930 \mathrm{~cm}^{-1}$ region have been reported as being characteristic of $\alpha$-helical keratin conformation.

In Figure 6 we compare the spectra of keratin, multiwalled carbon nanotubes, multiwalled carbon nanotubes oxidized, and three samples of experiments at $75^{\circ} \mathrm{C}$ with $\mathrm{MWOHs} /$ keratin $1: 1 \mathrm{wt} / \mathrm{wt}$ (CK7511), $65^{\circ} \mathrm{C}$ with $\mathrm{MWOHs} /$ keratin $1: 1 \mathrm{wt} / \mathrm{wt}(\mathrm{CK} 6511)$, and $55^{\circ} \mathrm{C}$ with $\mathrm{MWOHs} /$ keratin $1: 3 \mathrm{wt} / \mathrm{wt}$ (CK5513). Based on the characteristic peaks of keratin, MWNTs pristine, and MWOHs spectra, we can observe the covalent bond between the hydroxyl from carbonyl and carboxyl of MWOHs with different functional groups of keratin dialyzed. In samples CK7511, CK6511 and CK5513, it is possible see $v_{s}\left(\mathrm{SO}_{3}\right)$ at 1220 and $1035 \mathrm{~cm}^{-1}$ due to the stretching of sulphur-oxygen $[52,53]$. On the other hand, at $3443 \mathrm{~cm}^{-1}$ (associated with $\mathrm{O}-\mathrm{H}$ another at $1466 \mathrm{~cm}^{-1}$ ) in the samples grafting, we can see a widening in the spectra in this wavenumber, where it is clear the presence of $\nu(\mathrm{NH})$ at $3293 \mathrm{~cm}^{-1}$, that is, invisible in MWOHs and MWNTs.

To support the presence of keratin in the walls of carbon nanotubes, the studies of elemental analysis by combustion and X-ray Photoelectron Spectrometer are the key to that. With a quality control, the sulfanilamide was used as standard. The experimental results were $\mathrm{N}=16.24 \%, \mathrm{C}=41.79 \%$, $\mathrm{H}=4.64 \%$, and $\mathrm{S}=18.64 \%$, with the theoretical values of $\mathrm{N}=$ $16.25 \%, \mathrm{C}=41.81 \%, \mathrm{H}=4.65 \%$, and $\mathrm{S}=18.62 \%$, and the recovery percent is $99.94 \%, 99.95 \%, 99.78 \%$, and $100.11 \%$ for $\mathrm{N}, \mathrm{C}, \mathrm{H}$, and $\mathrm{S}$, respectively. Therefore, for the samples of 


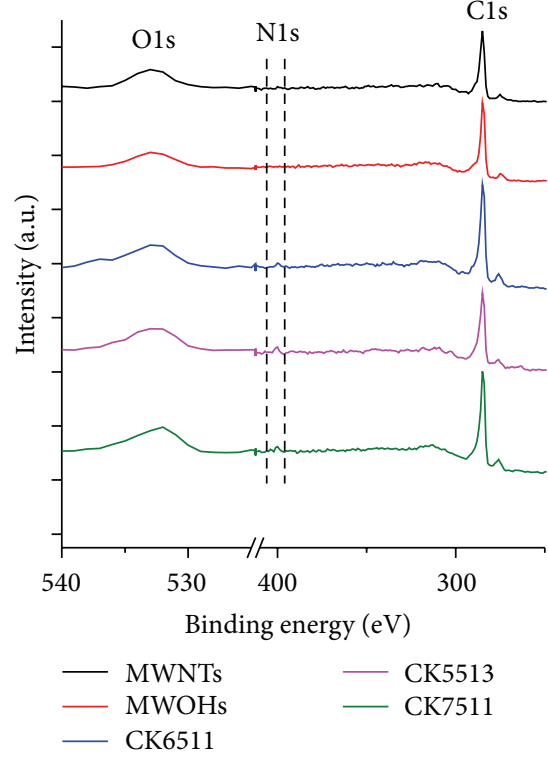

(a)

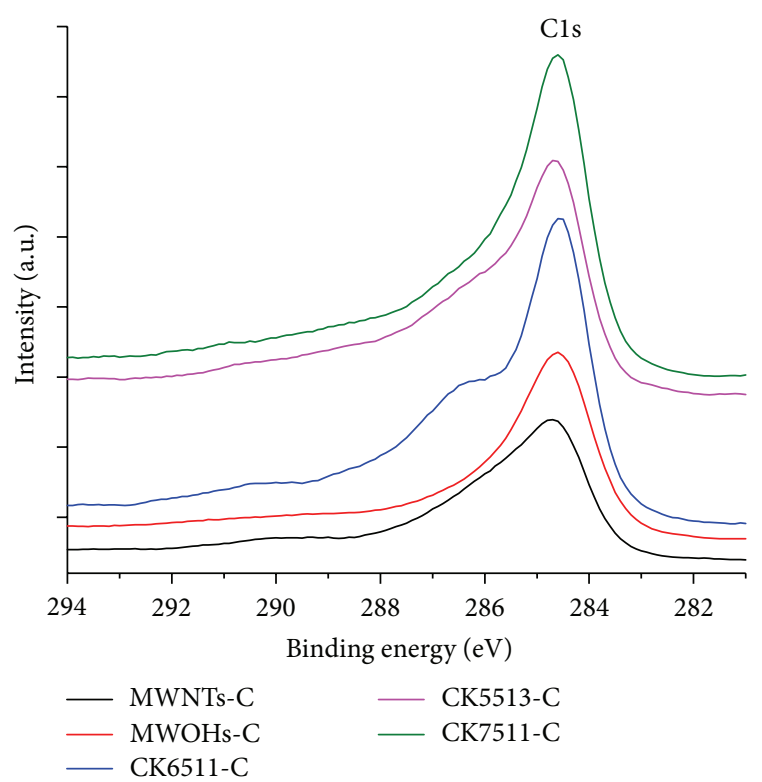

(c)

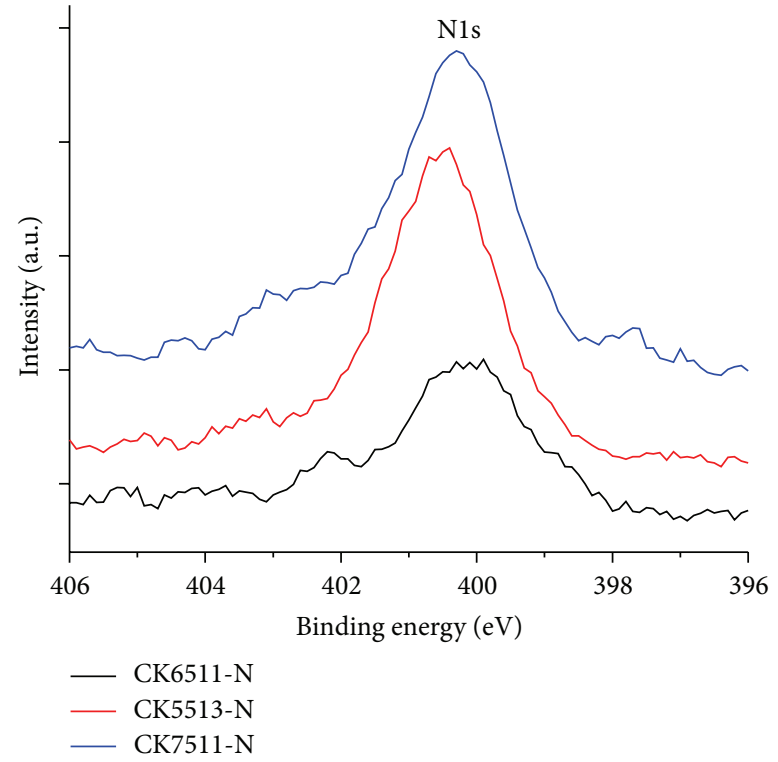

(b)

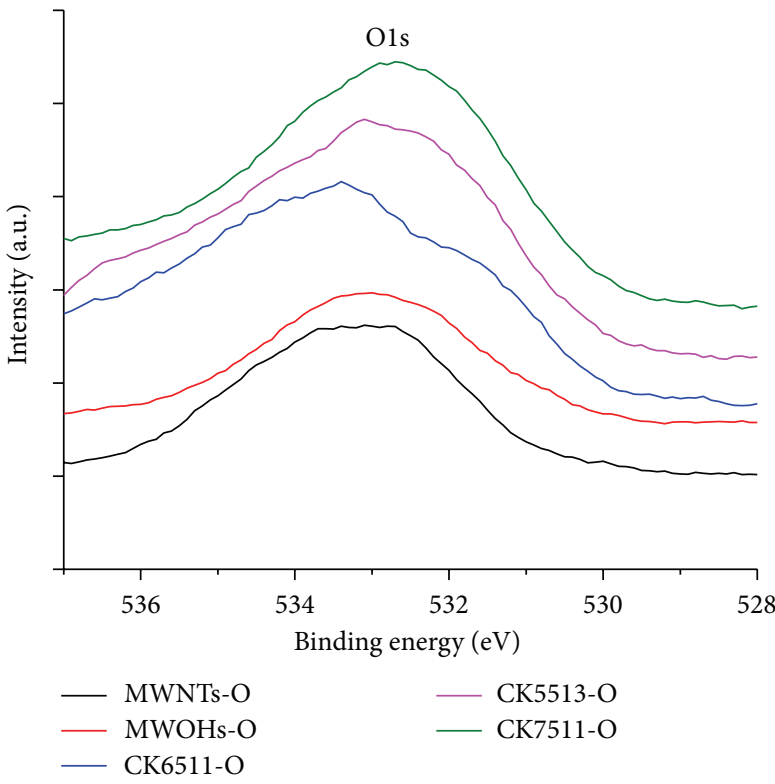

(d)

FIGURE 7: XPS with wide and narrow range of the samples MWNTs, MWOHs and the more representative samples of keratin-g-MWOHs (CK7511, CK5513, and CK6511).

MWNTs, MWOHs, and the most important assay (CK7511, CK5513, and CK6511), the results are shown in Table 4.

The presence of nitrogen in the samples is due to peptide bend [44], on the other hand, the presence of sulfur is due to cysteine containing amino acid responsible for the sulfursulfur bonding in the keratin [54]. The percentages of this characterization are lower to Bradford assay because the studies of elemental analysis by combustion are only the elemental percentage of nitrogen, hydrogen, carbon, and sulfur; however, Bradford assay determines the quantity of protein on the samples. With that analysis, the reduced percentage of nitrogen and sulfur elemental with relation to the amount of protein with Bradford assay is clear.

X-ray photoelectron spectroscopy (XPS) technique can give information about the chemical structure of carbon nanotubes [36]. But the most widely used data refers to the structure modification of the CNT walls due to the chemical interaction with organic compounds [36].

Compared to keratin-g-MWOHs samples with MWNTs and MWOHs in wide range of 250 to $540 \mathrm{eV}$ (Figure 7), the nitrogen into the nanotube structure is appreciable near to $400 \mathrm{eV}[36,55]$, characteristic of peptide bend of keratin 
$[46,47,56]$, and viewed very clearly in narrow range of 406$396 \mathrm{eV}$. On the other hand, in the narrow range of $294-281 \mathrm{eV}$ showed in Figure 7, the Cls peak exhibits a width according to oxidized and grafted the keratin on carbon nanotubes due to different hybridization $\mathrm{sp}^{2}$ and $\mathrm{sp}^{3}$ of the carbon with different elements of protein [57]. In a like manner, in Figure 7, the O1s peak exhibits the same behavior in the range of 537$528 \mathrm{eV}$.

\section{Conclusions}

The procedure developed in this paper was successful in grafting, in a controlled fashion, of keratin, obtained directly from chicken feathers, onto standard carbon nanotubes, provided they are properly functionalized. The spectroscopy analysis, both FTIR and Raman, in addition to confirming the covalent bonding involved, allowed to deduce the structural changes, both chemically and crystallographically speaking, associated with the grafting technology, which lead to variation on the properties of the resulting hybrid (i.e., organicinorganic). Finally, since our results showed the details of the interactions, the method developed could be employed for grafting other natural proteins onto carbonaceous nanostructures.

\section{Acknowledgments}

The authors are indebted to Dr. Genoveva HernándezPadrón, Mrs. Carmen Vazquez, Maria Lourdes Palma Tirado, and Mrs. Alejandra Núñez Pineda of Universidad Nacional Autonoma de Mexico and Dr. Gustavo López Téllez of Universidad Autonoma del Estado de Mexico for their technical support with the synthesis, FTIR, Raman, elemental analysis by combustion, and XPS studies. They thank the National Council of Science and Technology of Mexico (CONACyT) and FOMIX-CONACYT (ZAC-2010-C04-149908) for their financial support.

\section{References}

[1] E. Dervishi, Z. Li, Y. Xu et al., "Carbon nanotubes: Synthesis, properties, and applications," Particulate Science and Technology, vol. 27, no. 2, pp. 107-125, 2009.

[2] J. P. Salvetat, J. M. Bonard, N. B. Thomson et al., "Mechanical properties of carbon nanotubes," Applied Physics A, vol. 69, no. 3, pp. 255-260, 1999.

[3] V. N. Popov, "Carbon nanotubes: properties and application," Materials Science and Engineering R, vol. 43, no. 3, pp. 61-102, 2004.

[4] S. B. Sinnott and R. Andrews, "Carbon nanotubes: synthesis, properties, and applications," Critical Reviews in Solid State and Materials Sciences, vol. 26, no. 3, pp. 1-105, 2001.

[5] N. G. Sahoo, S. Rana, J. W. Cho, L. Li, and S. H. Chan, "Polymer nanocomposites based on functionalized carbon nanotubes," Progress in Polymer Science, vol. 35, no. 7, pp. 837-867, 2010.

[6] K. E. Geckeler and H. Nishide, Advanced Nanomaterials, WileyVCH, Weinheim, Germany, 2010.

[7] M. Wladyka-Przybylak, D. Wesolek, W. Gieparda, A. Boczkowska, and E. Ciecierska, "The effect of the surface modification of carbon nanotubes on their dispersion in the epoxy matrix," Polish Journal of Chemical Technology, vol. 13, no. 2, pp. 62-69, 2011.

[8] J. Venkatesan, Z. J. Qian, B. Ryu, N. Ashok Kumar, and S. K. Kim, "Preparation and characterization of carbon nanotubegrafted-chitosan-natural hydroxyapatite composite for bone tissue engineering," Carbohydrate Polymers, vol. 83, no. 2, pp. 569-577, 2011.

[9] Z. Spitalsky, D. Tasis, K. Papagelis, and C. Galiotis, "Carbon nanotube-polymer composites: chemistry, processing, mechanical and electrical properties," Progress in Polymer Science, vol. 35, no. 3, pp. 357-401, 2010.

[10] M. T. Byrne and Y. K. Guin'Ko, "Recent advances in research on carbon nanotube-polymer composites," Advanced Materials, vol. 22, no. 15, pp. 1672-1688, 2010.

[11] P. M. M. Schrooyen, P. J. Dijkstra, R. G. Oberthü, A. Bantjes, and J. Feijen, "Partially carboxymethylated feather keratins. 1. Properties in aqueous systems," Journal of Agricultural and Food Chemistry, vol. 48, no. 9, pp. 4326-4334, 2000.

[12] L. Rintoul, E. A. Carter, S. D. Stewart, and P. M. Fredericks, "Keratin orientation in wool and feathers by polarized Raman spectroscopy," Biopolymers, vol. 57, no. 1, pp. 19-28, 2000.

[13] S. Osswald, M. Havel, and Y. Gogotsi, "Monitoring oxidation of multiwalled carbon nanotubes by Raman spectroscopy," Journal of Raman Spectroscopy, vol. 38, no. 6, pp. 728-736, 2007.

[14] C. Velasco-Santos, A. L. Martínez-Hernández, and V. M. Castano, "Chemical functionalization on carbon nanotubes: principles and application," in Trends in Nanotechnology Research., E. V. de Dirote, Ed., pp. 51-78, Nova Science, 2004.

[15] C. E. Hong, J. H. Lee, P. Kalappa, and S. G. Advani, "Effects of oxidative conditions on properties of multi-walled carbon nanotubes in polymer nanocomposites," Composites Science and Technology, vol. 67, no. 6, pp. 1027-1034, 2007.

[16] H. Yu, Y. Jin, F. Peng, H. Wang, and J. Yang, "Kinetically controlled side-wall functionalization of carbon nanotubes by nitric acid oxidation," Journal of Physical Chemistry C, vol. 112, no. 17, pp. 6758-6763, 2008.

[17] J. Zhang, H. Zou, Q. Qing et al., "Effect of chemical oxidation on the structure of single-walled carbon nanotubes," Journal of Physical Chemistry B, vol. 107, no. 16, pp. 3712-3718, 2003.

[18] T. C. Hung, C. F. Chen, M. Chen, and C. C. Chen, "Quantitative limitation of active site and characteristics of chemical oxidized well-aligned carbon nanotubes," Thin Solid Films, vol. 516, no. 16, pp. 5236-5240, 2008.

[19] A. L. Martinez-Hernandez, C. Velasco-Santos, V. M. CastanoMeneses, and M. De Icaza, "Grafting of methyl methacrylate onto natural keratina," e-polymers, http://www.e-polymers .org/, 2003

[20] A. L. Martínez-Hernández, A. L. Santiago-Valtierra, and M. J. Alvarez-Ponce, "Chemical modification of keratin biofibres by graft polymerisation of methyl methacrylate using redox initiation," Materials Research Innovations, vol. 12, no. 4, pp. 184-191, 2008.

[21] M. M. Bradford, "A rapid and sensitive method for the quantitation of microgram quantities of protein utilizing the principle of protein dye binding," Analytical Biochemistry, vol. 72, no. 1-2, pp. 248-254, 1976.

[22] G. E. P. Box, W. G. Hunter, and J. S. Hunter, Estadistica Para Investigadores: Introduccion al Diseño de Experimentos, Analisis de Datos y Construccion de Modelos, Reverte, 1999. 
[23] R. Y. Sato-Berrú, E. V. Basiuk, and J. M. Saniger, "Application of principal component analysis to discriminate the Raman spectra of functionalized multiwalled carbon nanotubes," Journal of Raman Spectroscopy, vol. 37, no. 11, pp. 1302-1306, 2006.

[24] C. Thomsen and S. Reich, "Raman scattering in carbon nanotubes," Topics in Applied Physics, vol. 108, no. 1, pp. 115-234, 2006.

[25] H. Athalin and S. Lefrant, "A correlated method for quantifying mixed and dispersed carbon nanotubes: analysis of the Raman band intensities and evidence of wavenumber shift," Journal of Raman Spectroscopy, vol. 36, no. 5, pp. 400-408, 2005.

[26] H. Kataura, Y. Achiba, X. Zhao, and Y. Ando, "Resonance Raman scattering of multi-walled carbon nanotubes," in Proceedings of the Symposium-Amorphous and Nanoestructured Carbon, vol. 593, no. 1, pp. 113-118, December 1999.

[27] M. S. Dresselhaus, G. Dresselhaus, R. Saito, and A. Jorio, "Raman spectroscopy of carbon nanotubes," Physics Reports, vol. 409, no. 2, pp. 47-99, 2005.

[28] S. Gupta and R. J. Patel, "Changes in the vibrational modes of carbon nanotubes induced by electron-beam irradiation: resonance raman spectroscopy," Journal of Raman Spectroscopy, vol. 38, no. 2, pp. 188-199, 2007.

[29] A. Jorio, R. Saito, G. Dresselhaus, and M. S. Dresselhaus, "Determination of nanotubes properties by Raman spectroscopy," Philosophical Transactions of the Royal Society A, vol. 362, no. 1824, pp. 2311-2336, 2004.

[30] P. Delhaes, M. Couzi, M. Trinquecoste, J. Dentzer, H. Hamidou, and C. Vix-Guterl, "A comparison between Raman spectroscopy and surface characterizations of multiwall carbon nanotubes," Carbon, vol. 44, no. 14, pp. 3005-3013, 2006.

[31] H. M. Heise, R. Kuckuk, A. K. Ojha, A. Srivastava, V. Srivastava, and B. P. Asthana, "Characterisation of carbonaceous materials using Raman spectroscopy: a comparison of carbon nanotube filters, single- and multi-walled nanotubes, graphitised porous carbon and graphite," Journal of Raman Spectroscopy, vol. 40, no. 3, pp. 344-353, 2009.

[32] M. Zdrojek, W. Gebicki, C. Jastrzebski, T. Melin, and A. Huczko, "Studies of multiwall carbon nanotubes using raman spectroscopy and atomic force microscopy," Diffusion and Defect Data B, vol. 99-100, pp. 265-268, 2004.

[33] J. H. Lehman, M. Terrones, E. Mansfield, K. E. Hurst, and V. Meunier, "Evaluating the characteristics of multiwall carbon nanotubes," Carbon, vol. 49, no. 8, pp. 2581-2602, 2011.

[34] M. S. Dresselhaus and P. C. Eklund, "Phonons in carbon nanotubes," Advances in Physics, vol. 49, no. 6, pp. 705-814, 2000.

[35] R. A. DiLeo, B. J. Landi, and R. P. Raffaelle, "Purity assessment of multiwalled carbon nanotubes by Raman spectroscopy," Journal of Applied Physics, vol. 101, no. 6, Article ID 064307, 2007.

[36] T. Belin and F. Epron, "Characterization methods of carbon nanotubes: a review," Materials Science and Engineering B, vol. 119, no. 2, pp. 105-118, 2005.

[37] U. Kuhlmann, H. Jantoljak, N. Pfänder, P. Bernier, C. Journet, and C. Thomsen, "Infrared active phonons in single-walled carbon nanotubes," Chemical Physics Letters, vol. 294, no. 1-3, pp. 237-240, 1998.

[38] C. Velasco-Santos, Preparación y caracterización de compositos a partir de nanotubos de carbón [Ph.D. thesis], Universidad Autónoma de Querétaro, Queretaro, Mexico, 2003.

[39] L. Stobinski, B. Lesiak, L. Kövér et al., "Multiwall carbon nanotubes purification and oxidation by nitric acid studied by the FTIR and electron spectroscopy methods," Journal of Alloys and Compounds, vol. 501, no. 1, pp. 77-84, 2010.
[40] M. Jackson and H. H. Mantsch, "The use and misuse of FTIR spectroscopy in the determination of protein structure," Critical Reviews in Biochemistry and Molecular Biology, vol. 30, no. 2, pp. 95-120, 1995.

[41] A. Barth, "Infrared spectroscopy of proteins," Biochimica et Biophysica Acta, vol. 1767, no. 9, pp. 1073-1101, 2007.

[42] J. Bandekar, "Amide modes and protein conformation," Biochimica et Biophysica Acta, vol. 1120, no. 2, pp. 123-143, 1992.

[43] A. Barth and C. Zscherp, "What vibrations tell us about proteins," Quarterly Reviews of Biophysics, vol. 35, no. 4, pp. 369430, 2002.

[44] A. Barth, "The infrared absorption of amino acid side chains," Progress in Biophysics and Molecular Biology, vol. 74, no. 3-5, pp. 141-173, 2000.

[45] B. Stuart, Infrared Spectroscopy: Fundamentals and Applications, John Wiley \& Sons, New Jersey, NJ, USA, 2004.

[46] R. Schor and S. Krimm, "Studies on the structure of feather keratin I. X-ray diffraction studies and other experimental data," Biophysical Journal, vol. 1, no. 6, pp. 467-487, 1961.

[47] H. Panayiotou, Vibrational spectroscopy of keratin fibres: a forensic approach [Ph.D. thesis], Queensland University of Technology, 2004.

[48] S. Krimm, "Infrared spectra and chain conformation of proteins," Journal of molecular biology, vol. 4, no. 1, pp. 528-540, 1962.

[49] E. Jin, N. Reddy, Z. Zhu, and Y. Yang, "Graft polymerization of native chicken feathers for thermoplastic applications," Journal of Agricultural and Food Chemistry, vol. 59, no. 5, pp. 1729-1738, 2011.

[50] H. G. M. Edwards, D. E. Hunt, and M. G. Sibley, "FT-Raman spectroscopic study of keratotic materials: Horn, hoof and tortoiseshell," Spectrochimica Acta A, vol. 54, no. 5, pp. 745-757, 1998.

[51] J. T. Pelton and L. R. McLean, "Spectroscopic methods for analysis of protein secondary structure," Analytical Biochemistry, vol. 277, no. 2, pp. 167-176, 2000.

[52] J. S. Church and K. R. Millington, "Photodegradation of wool keratin: part I. Vibrational spectroscopic studies," Biospectroscopy, vol. 2, no. 4, pp. 249-258, 1996.

[53] K. R. Millington and J. S. Church, "The photodegradation of wool keratin. II. Proposed mechanisms involving cystine," Journal of Photochemistry and Photobiology B, vol. 39, no. 3, pp. 204212, 1997.

[54] J. R. Barone and W. F. Schmidt, "Polyethylene reinforced with keratin fibers obtained from chicken feathers," Composites Science and Technology, vol. 65, no. 2, pp. 173-181, 2005.

[55] P. Ayala, R. Arenal, M. Rümmeli, A. Rubio, and T. Pichler, “The doping of carbon nanotubes with nitrogen and their potential applications," Carbon, vol. 48, no. 3, pp. 575-586, 2010.

[56] R. D. B. Fraser and T. P. MacRae, "Surface lattice in $\alpha$-keratin filaments," International Journal of Biological Macromolecules, vol. 10, no. 3, pp. 178-184, 1988.

[57] R. Droppa Jr., P. Hammer, A. C. M. Carvalho, M. C. Dos Santos, and F. Alvarez, "Incorporation of nitrogen in carbon nanotubes," Journal of Non-Crystalline Solids, vol. 299-302, part 2, pp. 874-879, 2002. 

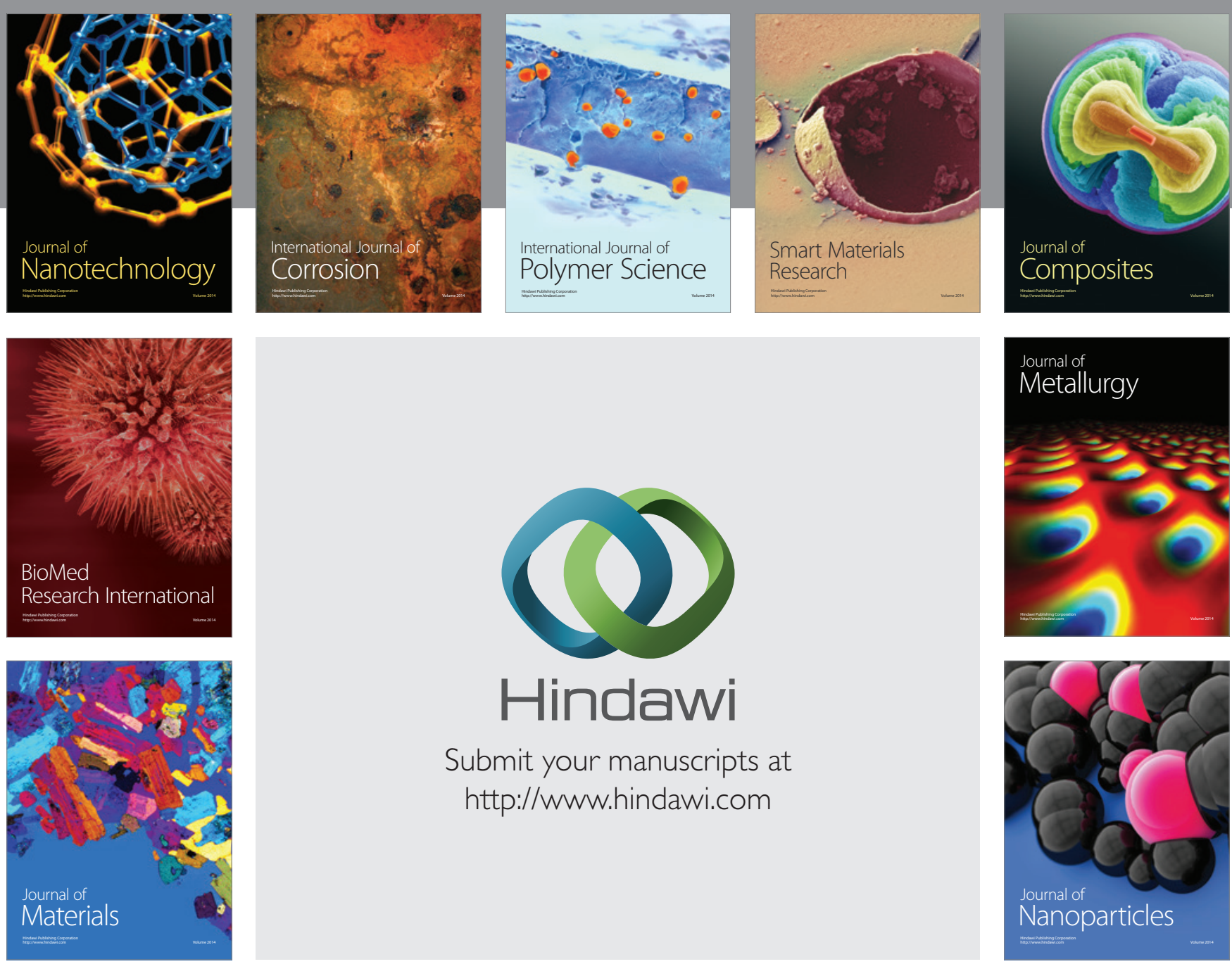

Submit your manuscripts at http://www.hindawi.com
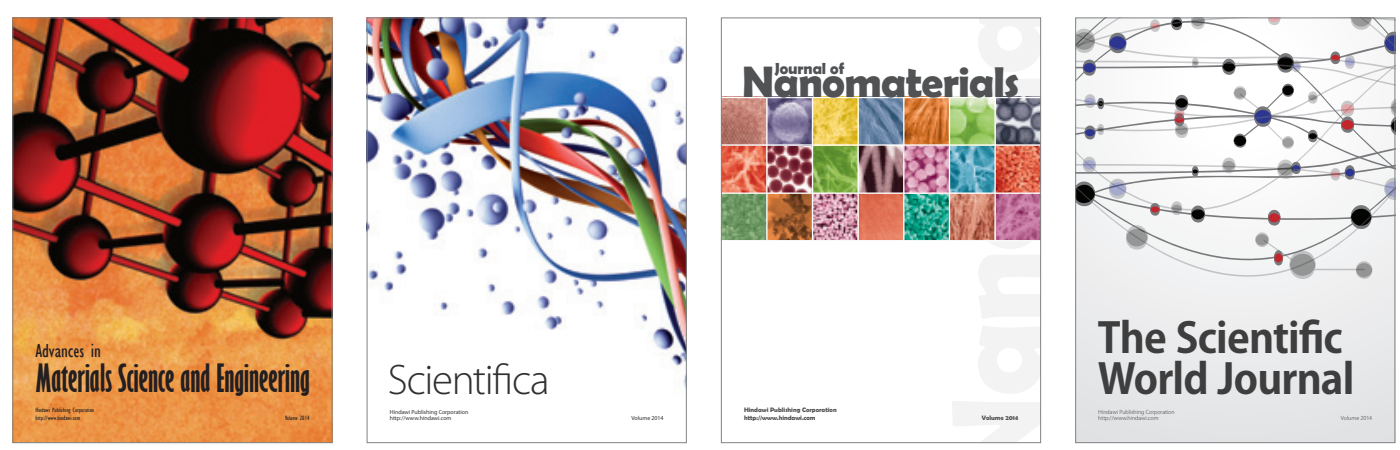

\section{The Scientific World Journal}
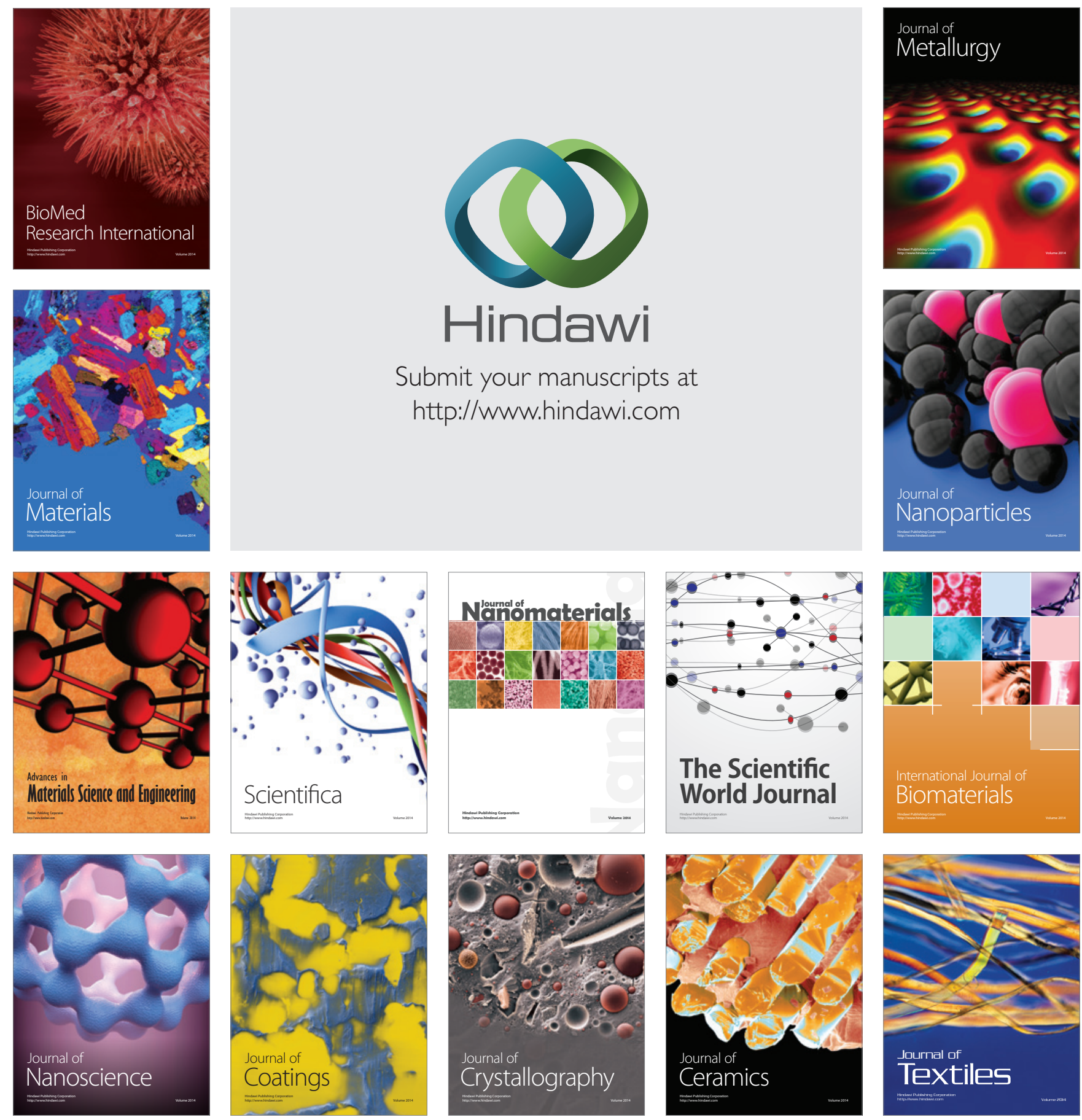